\title{
Guy de Maupassant: aspectos médicos de su creativa y desenfrenada vida
}

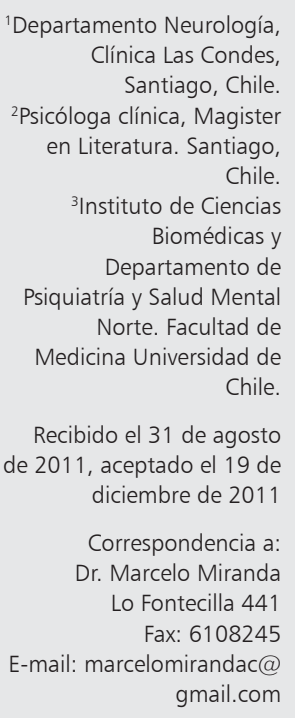

\author{
MARCELO MIRANDA C. ${ }^{1}$, NATALIA ROA V. ${ }^{2}$, M. LEONOR BUSTAMANTE C. ${ }^{3}$
}

\section{Guy de Maupassant: medical aspects of his lustful and creative life}

The French writer Guy de Maupassant is considered one of the most important story-tellers of all times. In his short life, he produced relevant works which are full of interesting medical descriptions, as sleep palsy and unconscious memory, depicted on his famous tale The Horla. Furthermore, many of his novels and tales contain precise and very insightful descriptions of physicians, many of whom he contacted because of suffering severe migraine. Maupassant became psychotic on his last years as a result of neurosyphilis and died in an asylum. In this review, we analyze some medical aspects of his intense life and provide references of unknown medical descriptions in his works.

(Rev Med Chile 2012; 140: 524-529).

Key words: Medicine in literature; Neurology; Psychiatry.
"Maupassant a quien se ha llamado maestro de la palabra precisa, nunca ha sido un mero tratante de palabras. Sus mercancías no han sido cuentas de vidrio, sino pulidas gemas, quizás no las más raras y preciosas, pero sí con las mejores aguas de su género".

Joseph Conrad.

"Entré en la vida literaria como un meteoro y saldré como un rayo".

Guy de Maupassant

$\longrightarrow$ uy de Maupassant (1850-1893) (Figura 1) es uno de los más notables cuentistas de la literatura universal. Proveniente de una familia de la aristocracia de la región de Normandía en Francia, vivió apenas 43 años ${ }^{1,2}$.

En 1880, con el apoyo de su admirado maestro, Gustave Flaubert, de quien se rumoreaba era hijo ilegítimo, inicia una carrera literaria de fama tras la publicación de "Bola de sebo". Este cuento inmortal formó parte del volumen colectivo "Las veladas de Medán”, piedra fundacional del movimiento naturalista ${ }^{1,2}$. En él hace un retrato magistral de la hipócrita y egoísta aristocracia francesa, se adelanta a dar notables atisbos de lo que posteriormente serán las narraciones de corte psicológico en sus descripciones de los personajes y, además, logra dar cuenta simbólicamente -tras el conflicto real en el trasfondo de la guerra franco prusiana- de un conflicto latente desde la Revolución entre los estamentos de la sociedad francesa. Maupassant fue uno de los pocos escritores franceses de esa época que hizo fortuna con sus obras y logró precozmente reconocimiento fuera de su país; en Rusia, por ejemplo, León Tolstoi e Iván Turgueniev valoraron mucho sus obras. De su primera novela, "Una vida", dijo Tolstoi que era la principal obra francesa posterior a "Los miserables" de Víctor Hugo ${ }^{4}$.

Para Maupassant, "el realista, si es artista, tratará, no de mostrarnos la fotografía trivial de la vida, sino darnos de ella una visión más completa, más penetrante, más convincente que la realidad misma. Cada uno de nosotros se hace una ilusión del mundo. Y el escritor no tiene otra misión que reproducir fielmente esa ilusión con todos los procedimientos artísticos que ha aprendido y de los que puede disponer" 5 . 


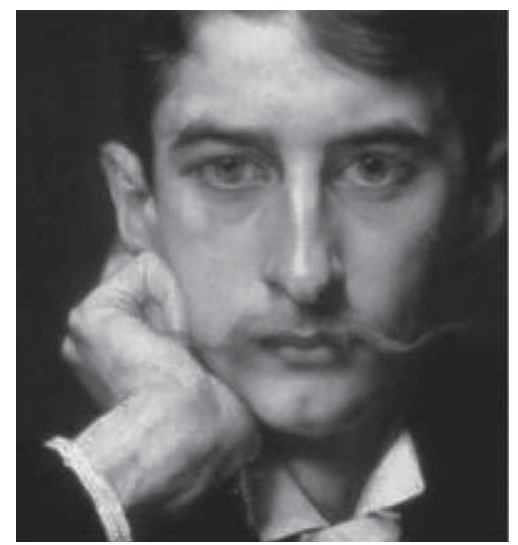

Figura 1. Maupassant en un poco conocido retrato de la época ${ }^{13}$.

Veremos así como Maupassant no sólo retrató su época, sino que intuyó aspectos del mundo psíquico que hasta hoy resultan apasionantes para los médicos y confirman la estrecha vinculación que existe entre el arte y la ciencia potenciándose ambas recíprocamente.

\section{Su opinión sobre J. M. Charcot}

Es llamativo que en la obra de este escritor francés aparezcan interesantes aspectos médicos de diversas condiciones neurológicas, lo que lo inscribe en la tradición de Charles Dickens y Wilkie Collins ${ }^{6}$. Hasta esa fecha estas manifestaciones estaban aún sin diagnóstico claro, lo que constituye una muestra del extraordinario poder de observación de Maupassant y de cómo el artista se adelanta a su época. En su afán de dar un retrato lo más real posible de lo que observaba, acudía con frecuencia durante los años 1884 a 1886 al Hospital de la Salpetriere ${ }^{7,8}$, donde pudo observar las clases prácticas de Jean Martin Charcot, el célebre neurólogo parisino. En estas clases magistrales Charcot entrenaba a sus renombrados discípulos, quienes bajo la influencia de su método y sus enseñanzas dieron forma a la psiquiatría académica moder$\mathrm{na}^{7}$. Asimismo estas clases estaban abiertas a todo público, especialmente a la aristrocracia francesa, siendo su nutrida concurrencia testimonio de la atracción que generaban. Era la época en que Charcot estaba en su apogeo; si bien sus demostraciones de casos de histeria e hipnotismo fascinaron a Maupassant, no dejó de formular una opinión crítica del neurólogo francés. Así, decía en una nota de 1882 sobre Charcot y la Histeria: ...Todos somos histéricos, de acuerdo a Charcot quien manipula a aquellas camareras histéricas en su modelo establecido en la Salpetriere; a la expensa de unas pobres mujeres neuróticas, el les inocula la locura y la transforma en demonios en instantes... Por otro lado a todos los grandes hombres les pasó también. Napoleón 1, Marat, Robespierre, Danton eran de tal manera. Uno a menudo escucha sobre Sarah Bernhardt, la célebre actriz,... "es una histérica". Los médicos nos enseñan también que el talento es una forma de histeria, y que él puede resultar de una lesión cerebral. Consecuentemente, el genio puede surgir de las 2 lesiones adyacentes, es decir, ¡histeria doble!... ....Charcot ha puesto de moda la histeria para explicar prácticamente cualquier exceso"9.

Luego, en su relato "Magnetismo" pone en boca de un protagonista la siguiente opinión sobre Charcot: "Con respecto al Sr. Charcot, de quien se dice es un sabio notable, me hace pensar en escritores como Edgar Allan Poe, que acaban por enloquecerse de tanto reflexionar acerca de extraños casos de locura. Charcot ha observado casos inexplicables y que siguen aún en todo lo desconocido de los trastornos nerviosos, él camina en lo desconocido que uno explora cada día, y como no siempre puede explicar lo que ve, quizás recurre demasiado a explicaciones eclesiásticas de tales misterios".

Su crítica a Charcot puede mirarse desde dos ángulos: por una parte, desde la intuición de que el ámbito que roza la locura excede a aquel que la ciencia puede abarcar y/o explicar completamente. Esto es algo que confirma en varias de sus obras, particularmente en "¿Quién sabe?", "El Doctor Heraclius Gloss", y en "El Horla”, y en ese sentido parece darnos a entender que la propuesta de Charcot, en su afán de ser integralmente abarcadora, generaría hipótesis pseudocientíficas. Y por otra, hay quizá una crítica velada a la ingenuidad de la aristocracia francesa que se deslumbra ante la "milagrosa curación" de los cuadros histéricos sin requerir mayores explicaciones, idealizando al maestro.

Maupassant, en tanto, desde la literatura, sin pretensión científica alguna hará aportes de extremo interés para la psiquiatría y la neurología.

\section{Maupassant y la locura}

“QQué profundo es el misterio de lo Invisible! No podemos sondearlo con nuestros miserables sentidos, 
con nuestros ojos que no saben captar ni lo muy pequeño ni lo muy grande, ni lo muy cercano ni lo muy lejano, ni los habitantes de una estrella, ni los habitantes de una gota de agua... Ni con nuestros oídos que nos engañan, pues nos transmiten las vibraciones del aire convertidas en notas sonoras. Son como hadas que hacen el milagro de transformar el movimiento en ruido".

La fascinación de Maupassant por lo desconocido y por la locura queda reflejada en este párrafo con que se inicia su cuento "La Sra. Herriot". Maupassant continúa diciendo:

"Me atraen los locos. Esas gentes viven en un país misterioso de sueños extraños, en esa nube impenetrable de la demencia donde todo lo que han visto en la tierra, todo lo que han amado, todo lo que han hecho, empieza de nuevo para ellos en una existencia imaginada al margen de todas las leyes que gobiernan las cosas y rigen el pensamiento humano. Para ellos no existe lo imposible, lo inverosímil desaparece, lo mágico se vuelve constante y lo sobrenatural familiar. Esa vieja barrera, la lógica, esa vieja muralla, la razón. Esa vieja rampa de las ideas, el buen sentido, se rompen, se abaten, se desmoronan ante su imaginación dejada en libertad, escapada al país ilimitado de la fantasía y que va dando brincos fabulosos sin que nada lo detenga. Para ellos todo ocurre y todo puede ocurrir. No se esfuerzan por vencer los acontecimientos. Dominar las resistencias, derribar los obstáculos. ;Basta un capricho de su voluntad llena de ilusión para que sean principes, emperadores o dioses, para que posean todas las riquezas del mundo, todas las cosas sabrosas de la vida, para que gocen de todos los placeres, para que sean siempre fuertes y jóvenes, siempre amados! Sólo ellos pueden ser felices en la tierra, porque para ellos, la Realidad ya no existe. Me gusta inclinarme sobre su espiritu vagabundo, como nos inclinamos sobre un abismo en cuyo fondo burbujea un torrente desconocido, que viene de no se sabe dónde y va a no se sabe dónde" 9 .

La atracción que le produce la locura parece derivar de la asociación que hace entre ella y la posibilidad de traspasar límites; esto es, la locura se visualiza como confiriendo una suerte de omnipotencia que permite diferenciarse de otros mortales y que, a la vez, permite explicar o asomarse a vislumbrar fenómenos que de otro modo resultan arcanos. Así, por ejemplo, le confesará a su amigo el escritor e influyente crítico Paul Bourget que ha visto a "su doble" ${ }^{10}$, temática que aparecerá en varias de sus obras, como figuras que aparecen en los espejos, "otros" al modo de El Horla, pseudo despersonalizaciones o fenómenos psicóticos quizás gatillados por el abuso de drogas por parte de Maupassant.

En realidad, varios de sus relatos se asoman al mundo de las perturbaciones mentales. Maupassant nos da una sorprendente descripción acerca de la vivencia de la locura; tenía un conocimiento personal de la patología ya que debió internar a su propio hermano afectado de un cuadro psicótico cuyo origen no es claro a partir de los datos disponibles pero que aparentemente correspondería a una neurolúes ${ }^{1}$. Más tarde, su conocimiento se haría más directo al experimentar él mismo síntomas somáticos y mentales.

\section{Parasomnia en el cuento El Horla}

En su célebre cuento "El Horla" (Figura 2), considerado uno de los mejores relatos de todos los tiempos, el protagonista es sobresaltado en las noches por un extraño ser invisible que llega a perturbarlo, hasta conducirlo a la locura9. La voz "Horla" es intraducible, pero existe acuerdo entre los estudiosos en torno a que Maupassant alude a la presencia de un "otro", de un ente ajeno a uno mismo ${ }^{5}$. Se ha pretendido ver en este cuento, desde su primera publicación, las manifestaciones de la neurolúes que afectó a Maupassant y que fue su causa de muerte. Sin embargo, hay una primera versión de este relato que data de 1886,7 años antes de su muerte y es improbable que lo haya escrito ya enfermo y que sobreviviera 7 años más sin terapia afectado por una parálisis general lúetica. En esa época sin tratamiento, un paciente con neurolúes no sobrevivía más de 3-4 años ${ }^{8,11}$. Desde su primer cuento de 1876, "La mano disecada" Maupassant manifestó interés por lo sobrenatural y la locura.

La historia comienza cuando, estando en su casa de campo, el personaje principal ve un barco que navega por un río cercano a su casa. Se trata de un barco brasileño, al cual saluda a lo lejos. Al saludar aquel extraño barco, que viene literalmente "del Otro Mundo", el protagonista permite, sin saberlo, la entrada del "Horla". El relato muestra con maestría la angustia que se va apoderando de un hombre que ve cómo ese algo o alguien está introduciéndose en su vida de forma velada e intangible. Empieza teniendo pesadillas en las que alguien intenta estrangularlo o bebe su sangre, 


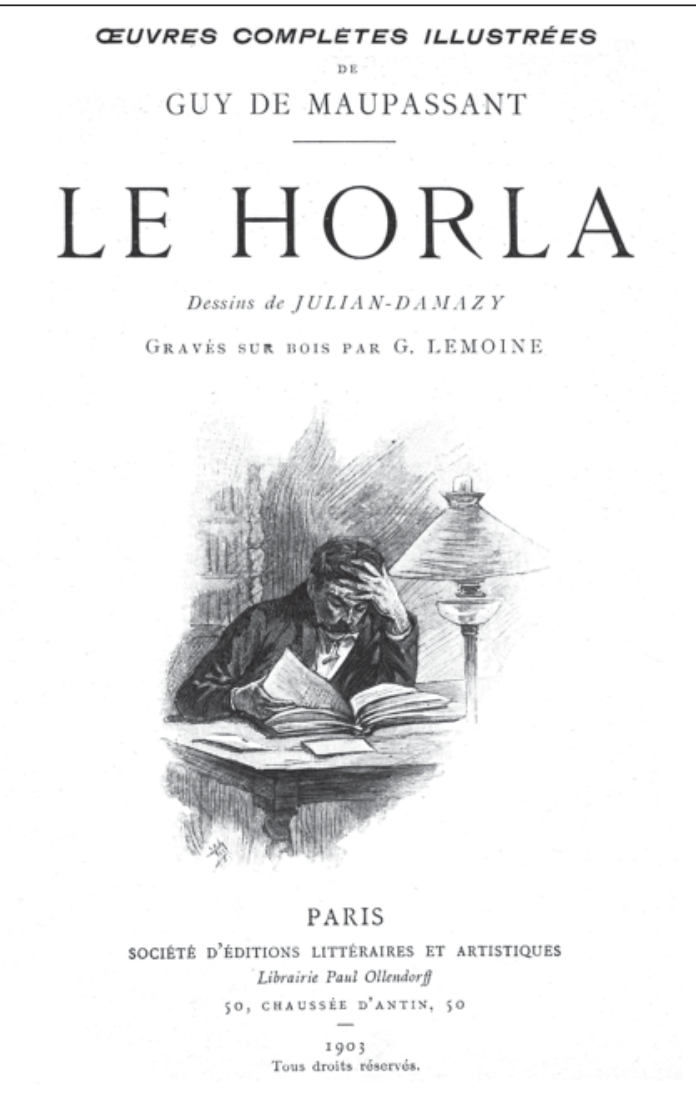

Figura 2. Una antigua edición de El Horla a los 10 años de fallecido Maupassant ${ }^{13}$.

y además descubre que alguien bebe el agua y la leche que él deja en su habitación. Por último, llegará a ser supuestamente poseído por la criatura, que gobierna todas sus acciones e incluso sus pensamientos hasta llevarlo al suicidio.

... Duermo durante dos o tres horas, y luego no es un sueño sino una pesadilla lo que se apodera de mí. Séperfectamente que estoy acostado y que duermo... lo comprendo y lo sé... y siento también que alguien se aproxima, me mira, me toca, sube sobre la cama, se arrodilla sobre mi pecho y tomando mi cuello entre sus manos aprieta y aprieta... con todas sus fuerzas para estrangularme.

Trato de defenderme, impedido por esa impotencia atroz que nos paraliza en los sueños: quiero gritar y no puedo; trato de moverme y no puedo; con angustiosos esfuerzos y jadeante, trato de liberarme, de rechazar ese ser que me aplasta y me asfixia, ipero no puedo!.
$Y$ de pronto, me despierto enloquecido y cubierto de sudor. Enciendo una bujía. Estoy solo.

Después de esa crisis, que se repite todas las noches, duermo por fin tranquilamente hasta el amanecer'.

Luego de terminar "El Horla", Maupassant advierte a su criado Tassart que "antes de ocho días verá usted que todos los periódicos publicarán que estoy loco. Que hagan lo que quieran, porque estoy sano de espíritu y sabía de sobra, al escribir este relato, lo que hacía. Es una obra de imaginación que impresionará al lector y hará que por su espalda pase más de un escalofrío".

Pero los artistas logran ir más allá de sus intuiciones. Así, cuando el protagonista del cuento siente la presencia del Horla detrás de él, intenta buscar una explicación científica al hecho. Dice Maupassant: "una extraña confusión se ha producido en mi cerebro, una de aquellas que los fisiólogos tratan de explicar en la actualidad... ¿No podría ser lo vivido un ejemplo de que una de las imperceptibles teclas de mi piano cerebral se haya bloqueado? La gente pierde, como resultado de un accidente, la capacidad de nombrar o verbalizar, hacer figuras o dar sólo fechas. En la actualidad ha sido posible la localización de todas las partes del pensamiento" "...

El protagonista describe, pues, lo que conocemos en la actualidad como una parálisis del sueño: un fenómeno del sueño REM en que el sujeto despierta en esta etapa de atonía mientras sueña y así experimenta esas extrañas sensaciones. Recién había sido descrito en la literatura médica en 1878 (Cheyre JM, comunicación personal).

El gran escritor norteamericano Howard Philip Lovecraft, creador del terror onírico, reconoció una fuerte influencia de este relato para realizar su obra maestra "Los mitos de Cthulhu".

\section{La memoria inconsciente}

En 1913 Proust publica "Por el camino de Swan" que contiene el famoso episodio en que el protagonista, al untar una magdalena en té, evoca la infancia ya perdida. Muchos la han considerado como la primera descripción literaria de la memoria inconsciente. Sin embargo, casi 30 años antes, Maupassant en "Enfermos y Médicos", escribe: "iSingular misterio es el recuerdo! Uno va despistado por las calles, bajo el primer sol de mayo, 
$y$ de repente, como si unas puertas durante mucho tiempo cerradas se abrieran en la memoria, cosas ya olvidadas regresan de nuevo a la mente. Pasan, seguidas por otras, nos hacen revivir horas pasadas, horas lejanas.

¿Por qué esas vueltas bruscas hacia antaño? ¿Quién lo sabe? Un olor que flota, una sensación tan ligera que ni la hemos notado, pero que uno de nuestros órganos reconoció, un escalofrío, incluso un destello de sol que daña la retina, un ruido tal vez, un nada que nos rozó en una circunstancia en un tiempo lejano y que volvemos a encontrar, vale para hacernos volver a ver de repente un país, unas gentes, unos acontecimientos desaparecidos de nuestro pensamiento.

¿Por qué un soplo de aire cargado de olores, de hojas bajo los castaños de los Campos Elíseos, evoca de repente un camino, un enorme camino, a lo largo de una montaña, en Auvernia?"'.

El concepto es muy similar y está, pues ya aquí. Pero hay más. En "Magnetismo", como destaca Armand Lanoux, relata la historia de un hombre que sueña con una mujer a la que conoce, pero no desea y a la que posee en sueños. A la mañana siguiente ella se entrega a él y se convierten en amantes por dos años. ¿Cómo explicárselo, pregunta el mismo narrador? Y responde que "quizá por una visión de ella que yo no había destacado y que me vino esa tarde como uno de esos llamados misteriosos e inconscientes de la memoria que nos representan a menudo cosas dejadas de lado por nuestra consciencia que han pasado desapercibidas ante nuestra inteligencia"1.

Este texto data de 1882, mientras que "La interpretación de los sueños" de Freud, recién de 1900 por lo que nuevamente se trata de una notable intuición; sólo que en la segunda obra, como dice Lanoux, la palabra inconsciente se transforma, de adjetivo en sustantivo ${ }^{10}$.

\section{Los médicos, los baños termales y su propia enfermedad}

En esa época era muy frecuente que los enfermos acudieran confiados a los baños para lograr una presunta cura de sus males. En varias de sus obras Maupassant hace mención de éstos, en particular en "Mont Oriol", ambientado en uno de ellos. En esta novela, con gran ironía se refiere Maupassant al carácter de los médi- cos, la competencia que entre ellos se da por los pacientes, la poca humildad e ignorancia de muchos y el aprovechamiento comercial de la confianza depositada por los enfermos. Es evidente que Maupassant refleja en estas obras un gran conocimiento de los médicos a los que debió consultar varias veces por severas jaquecas con componente ocular desde antes de $1880^{1}$. El renombrado oftalmólogo de esa época, Dr. Landol, lo evaluó por sus molestias en 1880 y describe: "En los inicios de 1880 Maupassant tenía una lesión en el ganglio paraocular, o más probablemente en un núcleo de células intracerebrales. La constatación de esta perturbación puede perfectamente corresponder a un diagnóstico de sifilis del sistema nervioso en un $80 \%$ de los casos $y$ de parálisis general en un 40\%"1.

Si bien en una carta datada de 1877 reconoce estar infectado de sifilis e incluso se vanagloria de ello, es muy improbable que las manifestaciones que empieza a presentar 2-3 años después sean de neurolúes; parecen más bien complicaciones de una jaqueca. Para alivio de su cefalea, Maupassant empieza a visitar los baños termales y a abusar del éter ${ }^{1,5}$. En esos años comienzan sus primeras alucinaciones visuales y sensaciones de desdoblamiento, lo que podemos interpretar como un cuadro piscógeno exógeno por drogas. Otro gran escritor de la época y amigo de Maupassant, Jean Lorrain, padeció idéntica adicción ${ }^{12}$. Estando ya enfermo en 1891, continúa con una vorágine de consultas con múltiples médicos franceses que le dan diversos diagnósticos e ineficaces terapias.

En 1889, debió internar a su hermano menor, Hervé, en un sanatorio mental afectado también por una parálisis general, quien en el momento de ingresar le grita: " YYo no estoy loco, tú eres el único loco en la familia!!”.

Maupassant no logró una relación estable con ninguna mujer: tuvo un excesivo apego por su madre a quien le debió su gran pasión por la literatura. La temprana separación de sus padres, el poco contacto con su padre a quién casi no conoció, y la especial relación de dependencia con su madre, probablemente son factores que influyeron en su especial conducta con las mujeres $^{1}$; a pesar de que alardea de sus conductas desenfrenadas hay muchos gestos de misoginia y no es casual que en su obra, las prostitutas suelan encarnar los valores morales frente a 


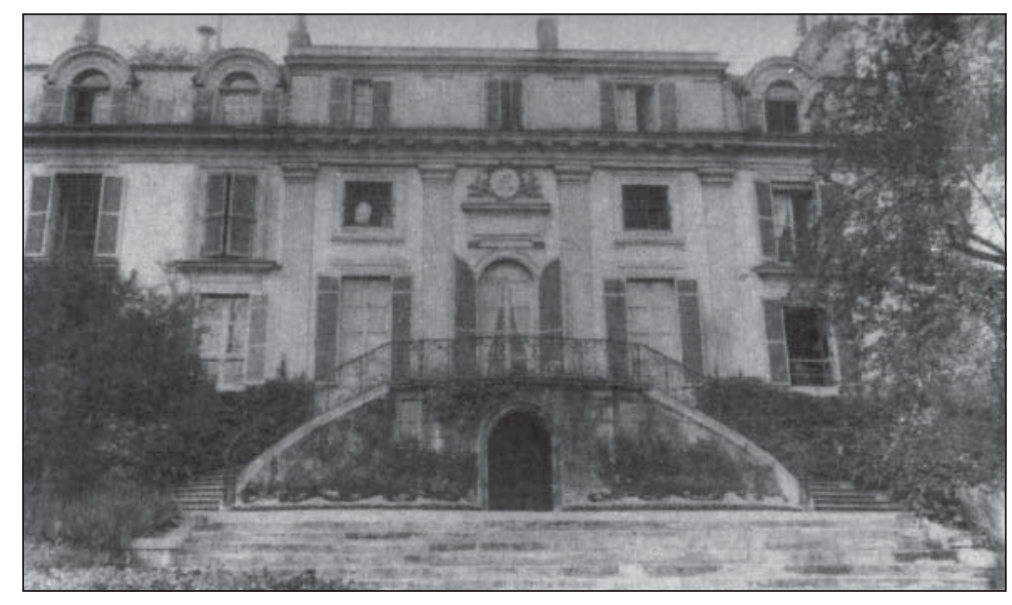

Figura 3. El sanatorio del Dr. Blanche, en París, donde Maupassant fue internado al desarrollar una parálisis general ${ }^{13}$. otras mujeres más cargadas de hipocresía. A ello se agrega un ánimo poco estudiado, pero que da algunos índices que podrían dar cuenta de una inestabilidad ${ }^{1,11}$.

En 1891, ya tiene claros signos síntomas de neurolúes producto de una vida desenfrenada; tanto es así que pone en palabras de uno de sus personajes lo siguiente: "entre los 18 y 40 años, el hombre puede llegar a poseer al menos 300 mujeres", lo que refleja muy probablemente su propia experiencia ${ }^{1}$. Ese año hace su testamento y le comenta a su criado que se ha encontrado con un fantasma: "Ese fantasma era yo mismo ...Ha venido a mi lado... No me ha dicho nada... Simplemente se ha encogido de hombros con desprecio... Me detesta... Francois, no olvide cerrar todas las puertas con doble llave"s.

A partir de entonces son cada vez más frecuentes los episodios de locura, incluido un doble intento de suicidio, con una pistola primero $y$ luego con un estilete con el que intenta cortarse el cuello. En 1892 es internado en un sanatorio (Figura 3) donde continúan sus delirios místicos y de mitomanía ${ }^{1}$.

Falleció en 1893, legando una obra literaria extraordinaria y un mundo psíquico fascinante para los estudiosos de la mente, que para él se convirtió en tenebroso. No en vano, sus últimas palabras fueron: "Oscuridad, oscuridad"s.

\section{Referencias}

1. Troyat H. Maupassant. Monte Avila Editores. Caracas. 1989.

2. Ruiz L. Prólogo en Guy de Maupassant. Obras Completas. Editorial Aguilar 1961.

3. Savinio A. Maupassant y el otro. Bruguera. Madrid 1983.

4. Tolstoi L. Zola, Dumas y Maupassant. En Obras. Aguilar, Madrid. 1961.

5. Armiño M. En Maupassant. Cuentos Completos de terror, locura y muerte. Valdemar. Barcelona. 2011.

6. Miranda M. William Wilkie Collins: la medicina como recurso en la literatura de ficción. Rev Med Chile 2011 (en prensa).

7. Bogousslavsky J, Moulin T. Birth of Modern Psychiatry and the Death of Alienism: The Legacy of Jean-Martin Charcot. Front Neurol Neurosci. Basel, Karger, 20.

8. Critchley M. Four Famous Luetics. Proc Roy Soc Med 1969; 62: 669-73.

9. Maupassant G. Obras Completas. Editorial Aguilar 1961.

10. Lanoux. A. Préface a Maupassant Guy, Contes et Nouvelles, Gallimard, Paris 1974.

11. Koehler P. About Medicine and the Arts: Charcot and French Literature at the fin-de-siecle. Journal of the History of Neurosciences 10: 27-40, 2001.

12. Lorrain J. Relatos de un bebedor de éter. Editora Caja Negra, Buenos Aires, 2011.

13. http://www.maupassantiana.fr/visitado 26 de agosto de 2011. 